\title{
Early recognition of risk factors for adverse outcomes during hospitalization among Medicare patients: a prospective cohort study
}

Jeff Borenstein ${ }^{1 * \dagger}$, Harriet Udin Aronow ${ }^{2 \dagger}$, Linda Burnes Bolton ${ }^{3}$, Jua Choi ${ }^{3}$, Catherine Bresee ${ }^{3}$ and Glenn D Braunstein ${ }^{3}$

\begin{abstract}
Background: There is a persistently high incidence of adverse events during hospitalization among Medicare beneficiaries. Attributes of vulnerability are prevalent, readily apparent, and therefore potentially useful for recognizing those at greatest risk for hospital adverse events who may benefit most from preventive measures. We sought to identify patient characteristics associated with adverse events that are present early in a hospital stay.

Methods: An interprofessional panel selected characteristics thought to confer risk of hospital adverse events and measurable within the setting of acute illness. A convenience sample of 214 Medicare beneficiaries admitted to a large, academic medical center were included in a quality improvement project to develop risk assessment protocols. The data were subsequently analyzed as a prospective cohort study to test the association of risk factors, assessed within 24 hours of hospital admission, with falls, hospital-acquired pressure ulcers (HAPU) and infections (HAl), adverse drug reactions (ADE) and 30-day readmissions.

Results: Mean age $=75( \pm 13.4)$ years. Risk factors with highest prevalence included $>4$ active comorbidities (73.8\%), polypharmacy (51.7\%), and anemia (48.1\%). One or more adverse hospital outcomes occurred in 46 patients (21.5\%); 56 patients (26.2\%) were readmitted within 30 days. Cluster analysis described three adverse outcomes: 30-day readmission, and two groups of in-hospital outcomes. Distinct regression models were identified: Weight loss $(\mathrm{OR}=3.83 ; 95 \% \mathrm{Cl}=1.46,10.08)$ and potentially inappropriate medications $(\mathrm{OR}=3.05 ; 95 \% \mathrm{Cl}=1.19,7.83)$ were associated with falls, HAPU, procedural complications, or transfer to intensive care; cognitive impairment ( $\mathrm{OR}=2.32$; $95 \% \mathrm{Cl}=1.24,4.37)$, anemia $(\mathrm{OR}=1.87 ; 95 \% \mathrm{Cl}=1.00,3.51)$ and weight loss $(\mathrm{OR}=2.89 ; 95 \% \mathrm{Cl}=1.38,6.07)$ were associated with $\mathrm{HAl}, \mathrm{ADE}$, or length of stay $>7$ days; hyponatremia $(\mathrm{OR}=3.49 ; 95 \% \mathrm{Cl}=1.30,9.35)$, prior hospitalization within 30 days $(\mathrm{OR}=2.66 ; 95 \% \mathrm{Cl}=1.31,5.43)$ and functional impairment $(\mathrm{OR}=2.05 ; 95 \% \mathrm{Cl}=1.02,4.13)$ were associated with 30-day readmission.
\end{abstract}

Conclusions: Patient characteristics recognizable within 24 hours of admission can be used to identify increased risk for adverse events and 30-day readmission.

Keywords: Frailty, Readmissions, Patient safety, Medicare, Hospitalized elderly

\footnotetext{
* Correspondence: jeff.borenstein@cshs.org

†Equal contributors

'Applied Health Services Research, Cedars-Sinai Health System, 8700 Beverly

Blvd, Los Angeles, CA 90048, USA

Full list of author information is available at the end of the article
} 


\section{Background}

The Institute of Medicine report on patient safety in the U.S. health care system, To Err Is Human, highlighted the unacceptably high incidence of adverse events during hospitalization [1]. More recently, the Office of the Inspector General reported that $13.1 \%$ of hospitalized patients with Medicare insurance experienced an adverse event that resulted in harm [2]. Clearly, opportunities to improve patient safety remain, particularly among Medicare beneficiaries.

Frailty is a term describing a state of general debility associated with decline, disability, loss of independence, susceptibility to iatrogenic complications, and poor health outcomes $[3,4]$. As such, frailty is a potentially useful construct for identifying those within the Medicare population who are most vulnerable to adverse events associated with hospitalization. Prompt recognition of frailty could facilitate communication, multidisciplinary care coordination, risk reduction interventions, prognostication, and appropriate treatment plan development $[5,6]$.

Although frailty has long recognized as a clinical syndrome within the field of geriatrics, there is no universally accepted definition $[7,8]$. Alternative approaches to identifying frailty employ significantly differing methods, and vary in their strengths and limitations [9]. Existing models of frailty were primarily developed in outpatient cohorts, and are therefore challenging to apply to an inpatient population [10-13]. A validated and widely used measure defines frailty as a deficit in at least three of five measures of function, one of which is walking speed [10]. This functionally-based strategy can be difficult to assess in the setting of acute illness. Frailty indices that quantitate the sum of accumulated deficits across a wide range of possibilities are somewhat complex to apply in practice, as they typically require inclusion of at least 30 or more variables [14]. 'Vulnerability', a related construct, represents an impending risk of functional decline, and can be assessed with a simple screening tool, the Vulnerable Elders Survey-13 (VES-13) [11]. Both frailty and vulnerability describe a health state that is fragile, associated with adverse health events, and more easily recognized with a global view of wellness rather than any specific medical condition. The VES-13 requires patient self-report of function over the preceding 4 weeks, which could also be affected by factors leading to hospitalization. None of these approaches to identifying frailty, as functional deficit, a composite index, or vulnerability to impending decline, have been wellvalidated within a medical inpatient cohort.

We conducted a prospective cohort study in a convenience sample of Medicare patients to test the hypothesis that a set of risk factors associated with frailty and identifiable within 24 hours of hospital admission would be associated with adverse events during hospitalization.

\section{Methods}

Patient characteristics that could be potentially associated with adverse events during hospitalization were derived by consensus by an interprofessional quality improvement (QI) workgroup. Sources for candidate variables included a search of the PubMed database using the terms "frail", "frailty", "vulnerable", "vulnerability, and "fragile", and discussions with local topic experts. A Delphi panel of physicians, nurses, and allied health care providers selected items readily measurable, identifiable on admission, thought to have a relatively high likelihood of an association with adverse health outcomes and be potentially amenable to risk reduction strategies $[1,15]$. Given the large number of candidate variables $[8,16]$, we further sought to identify a subset of practical attributes that were clinically relevant to the patient population at our institution and representative of a multidisciplinary perspective. To this end, the subset of risk factors for consideration were selected over the course of three meetings in which physicians and nurses were equally represented and comprised approximately twothirds of the 20-25 attendees. The remainder of attendees were mostly allied health care professionals, as described in Additional file 1 Following a baseline vote, rounds of discussion and anonymous re-voting continued until consensus was achieved, defined as all votes falling within one of the mode on a one to nine scale of increasing disagreement, where scores of 1-3 indicated agreement. Exploratory variables included admission from a skilled nursing facility [5], age $\geq 80$ years $[17,18]$, presence of a feeding tube [19], and decubitus ulcers noted on admission [20]. Additional exploratory variables include the presence of four or more active comorbid conditions, anemia, cognitive impairment, deconditioning, dehydration, a positive screen for depression, functional impairment, high burden of comorbid illness, hyponatremia, hypoalbuminemia, polypharmacy, early readmission, and recent unintentional weight loss. Definitions of these terms are provided in Additional file 1.

The candidate set of risk factors was then evaluated in a convenience sample of patients ages 35 years and older with Medicare insurance from a total of $n=653$ admitted to general medical/surgical units within our institution in September 2010. Only patients who were accessible to the nurses performing the assessments and who agreed to the extra assessments and to have their chart information reviewed were included. Patients were interviewed and their charts reviewed within 24 hours of admission. Other patient characteristics were derived from a variety of sources: Nurses administered the VES-13, and assessments of functional status (Katz Assessment for Functional Status) [21], cognitive impairment (Brief Interview for Mental Status) [22] and symptoms of depression (Patient Health Questionnaire-2) [23]. Clinical pharmacists documented the use of potentially inappropriate medications prior to admission 
$[24,25]$, and adverse drug events during hospitalization. The latter were identified by the occurrence of a sentinel event or "trigger" and confirmed with chart review [26]. Specific criteria used in medication review are described in Additional file 1. Patient falls, hospital-acquired pressure ulcers, and readmissions within 30 days of discharge were obtained from administrative and patient safety databases, and medical record auditing. Physicians blinded to the initial nursing assessment reviewed medical charts recorded all other clinical outcomes.

This work of the Frailty workgroup was provided administrative approval by the Cedars-Sinai Medical Center Institutional Review Board as an evidence-based (QI) project. For the purposes of the current research analyses, the data from the QI project were de-identified and used secondarily. The Institutional Review Board approved request for waiver for the need to obtain consent from participants.

\section{Statistical analysis}

Research analyses were performed using SAS (The SAS Institutes Incorporated, Cary, $\mathrm{NC}$, release 9.3). Descriptive statistics were produced for all frailty factors and adverse outcomes. (see Table 1) Associations among adverse outcome variables were assessed with Spearman rank correlations. Due to multiple low frequency events and high inter-correlation among adverse outcomes data, variable cluster analysis was performed to develop a smaller number of independent outcomes [27]. Variable clustering was performed using a linear combination of the first principal component and following a hierarchical divisive structure. The final number of clusters of adverse outcome events was determined empirically and confirmed clinically. Internal consistency of each cluster was evaluated with Cronbach's alpha. Un-adjusted and then multivariable, adjusted, logistic regression modeling were used to determine the set of frailty factors that were predictive of the presence or absence of any one or more events within each adverse outcome cluster using the selection criteria as described by Collett [28]. The final multivariable models were assessed for goodness-of-fit by inspection of the Pearson residuals for identification of observations poorly accounted for in each model. The c-statistic (the area under the receiver-operator curve) was computed for each multivariable model to evaluate model discrimination. The cumulative effect of each frailty characteristic on adverse events was also tested by Spearman rank correlation. Data are presented as means $+/$ - standard deviations, or counts and percentages. Data were considered statistically significant where $\mathrm{p}<.05$.

\section{Results}

\section{Patient characteristics}

The study cohort was comprised of 214 patients admitted to our institution in September 2010. Mean patient age was $75+/-13.4$ years, and mean length of hospital stay was $5.8+/-6.26$ days. The most prevalent risk factors were four or more active comorbidities (73.8\%), polypharmacy (51.7\%), and anemia (48.1\%) (Table 1). Among those able to complete the VES-13 ( $\mathrm{n}=161,75.2 \%)$, nearly two-thirds $(\mathrm{n}=106,65.8 \%)$ met criteria for vulnerability (mean score $5.0+/-2.7$ ). All frailty characteristics, with the exception of a hospitalization within 30 days prior to admission, evidence of recent weight loss, and the presence of a feeding tube on admission, were associated $(\mathrm{p}<.05)$ with vulnerability per the VES-13 scale (data not shown). Over half (54\%) of patients were prescribed one or more potentially inappropriate medications prior to admission, of which major tranquilizers were the most common subcategory.

\section{Adverse outcomes of hospitalization and cluster analysis}

Adverse patient outcomes and their frequencies are presented in Table 2. The incidence of patient readmissions within 30 days of hospital discharge and a length of hospital stay (LOS) 7 days or longer were $21.0 \%$ and $26.2 \%$, respectively. In all, 41 patients (19.2\%) experienced any adverse event during hospitalization, with adverse drug events being the most common (11.7\%). Statistically significant intercorrelations $(\mathrm{P}<.05)$ among adverse outcomes were observed for all variables except hospital-acquired infections and readmissions with 30 days (data not shown).

Cluster analysis identified three distinct outcome categories: Readmission within 30 days post-discharge and two interrelated groups (clusters) of adverse events during hospitalization: The first cluster was comprised of falls, hospital-acquired pressure ulcers, complications of a medical procedure, and transfers to an intensive care unit (Cronbach's alpha $=0.685$ ). The second cluster was comprised of adverse drug events, length of stay 7 days or longer, and hospital-acquired infections (Cronbach's alpha $=0.548)$. Results of the cluster analysis did not differ significantly when the population was restricted to patients age 65 and older.

\section{Relationship of potential characteristics of a frailty in a medicare population to adverse outcomes}

Associations between individual characteristics and the three outcome categories identified by cluster analysis are displayed in Table 3. Significant associations are bolded. No single characteristic was significantly associated with all three outcomes.

The final adjusted regression models (Table 4) resulted in seven frailty characteristics emerging as significant independent predictors in the three logistic regressions of adverse outcome clusters and readmissions: cognitive impairment; anemia; recent unintentional weight loss; any potentially inappropriate medication; hyponatremia; hospitalization within preceding 30 days; and functional impairment. Only one variable, unintentional weight 
Table 1 Study cohort demographics

\begin{tabular}{l} 
Description \\
\hline Female \\
Age (years) \\
$<65$ \\
$65-79$ \\
$>80$ \\
Race \\
White \\
Black \\
Other \\
Secondary insurance type \\
Commercial PPO \\
Commercial Indemnity \\
Medicaid Indemnity \\
Other/Unknown \\
Discharge destination \\
Home/self-care \\
Home health care \\
Skilled Nursing Facility \\
Hospice \\
Expired \\
Other
\end{tabular}

Comorbidities ( $\mathrm{n}$ and\% of total for each)

Myocardial infarction

Heart failure

Ischemic heart disease

COPD $^{b}$

Peripheral vascular disease

Diabetes

Cancer

Dementia

Hepatic disease

Mild renal disease ${ }^{c}$

Moderate/severe renal disease

Frailty characteristics ( $\mathrm{n}$ and\% of total for each)

Admitted from a skilled nursing facility

Ages 80 years and older

Anemia

Charlson Comorbidity Index Score > =4

Cognitive impairment

Deconditioning

Decubitus ulcer

Dehydration

Depression screen positive*

Feeding tube present at admission
Table 1 Study cohort demographics (Continued)

\begin{tabular}{lr}
\hline Four or more active comorbid conditions & $158(73.8)$ \\
Functional impairment & $77(36.0)$ \\
Hyponatremia & $20(9.3)$ \\
Malnutrition & $27(12.6)$ \\
Potentially inappropriate medications & $72(33.6)$ \\
Use of a major tranquilizer & $49(22.9)$ \\
Polypharmacy** & $106(51.7)$ \\
Early readmission: & \\
$\geq 1$ within the past 30 days & $59(27.6)$ \\
$\geq 2$ within the past 6 months & $49(22.9)$ \\
Recent unintentional weight loss & $41(19.2)$ \\
\hline
\end{tabular}

$61(28.5)$

41 (19.2)

78 (36.4)

34 (15.9)

$112(52.3)$

$46(21.5)$

$36(16.8)$

$6(2.80$

$3(1.4)$

$11(5.1)$

$22(10.3)$

$36(16.8)$

$21(9.8)$

28 (13.1)

$28(13.1)$

$66(30.8)$

$44(20.6)$

$28(13.1)$

$14(6.6)$

24 (11.2)

$72(33.6)$

22 (10.3)

89 (41.6)

103 (48.1)

74 (34.6)

76 (35.5)

28 (13.1)

$17(7.9)$

84 (39.3)

75 (42.1)

8 (3.7)

${ }^{\mathrm{a} P P O}=$ Preferred Provider Organization; ${ }^{\mathrm{b}} \mathrm{COPD}=$ chronic obstructive pulmonary disease; ' Renal disease severity determined by estimated creatinine clearance: $\mathrm{mild}=60-89 \mathrm{ml} / \mathrm{min}$; moderate $/$ severe $=<60 \mathrm{ml} / \mathrm{min}$ or dialysis dependent. Data available from only $\left({ }^{*}\right) n=178$ or $\left({ }^{* *}\right) n=205$.

loss, was associated with both inpatient outcome clusters. Hyponatremia was an independent risk factor of readmission within 30 days, irrespective of comorbid renal disease, diabetes, or heart failure. Furthermore, we found that the incidence of adverse outcomes increased proportionally to the number of associated frailty characteristics $(\mathrm{p}<.001$ for both comparisons, Figure 1$)$.

\section{Discussion}

In this prospective study of Medicare beneficiaries, characteristics readily identifiable on hospital admission were associated with an increased risk of adverse events and subsequent hospitalization within 30 days of discharge. Potential risk factors were derived from published literature on frailty, a construct developed largely in the ambulatory setting. Candidate variables were selected by a multidisciplinary panel that took into consideration practical constraints associated with acute illness, such as limitations on mobility and strength.

The goal of this research was to identify patient characteristics associated specific inpatient adverse events as a basis for subsequent targeting of risk mitigation efforts. We chose to perform the study in a cohort of Medicare patients due to their relatively high risk of adverse events during hospitalization [29]. As a consequence, the majority of patients included in the analysis $(81.3 \%)$ were 65 years old and older, over half of whom $(51.2 \%)$ were at least 80 years of age. The projected rapid growth of the population of older adults, and the associated rise in anticipated use of health services, makes improving the inpatient safety among the elderly an urgent priority [30,31]. Adverse medical events occur with greater frequency among the elderly, and can lead to functional decline, decreased quality of care, and increased costs [32,33]. The elderly also account for the greatest proportion of the rising number of hospital admissions, but performance on 
Table 2 Incidence of adverse outcomes ( $N=214$ patients)

\begin{tabular}{lr}
\hline Outcome & $\mathbf{n ~ ( \% )}$ \\
\hline Any adverse events during hospitalization & $46(21.5)$ \\
Adverse drug events & $25(11.7)$ \\
Hospital-Acquired Infections & $11(5.1)$ \\
Transfer to intensive care & $12(5.6)$ \\
Complications of a medical procedure & $12(5.6)$ \\
Hospital-acquired pressure ulcers & $2(0.9)$ \\
Falls during hospital & $5(2.3)$ \\
Length of hospital stay 7 days and longer & $56(26.2)$ \\
Mortality during hospitalization & $3(1.4)$ \\
Readmission within 30 days of hospital discharge & $45(21.0)$ \\
\hline
\end{tabular}

Table 3 Unadjusted logistic regression modeling

\begin{tabular}{|c|c|c|c|}
\hline Description & $\begin{array}{l}\text { Falls, HAPU }{ }^{a}, P^{b} \text {, } \\
\text { ICUc transfer } \\
\text { [Cluster 1] } \\
\text { OR }(95 \% \mathrm{Cl})\end{array}$ & $\begin{array}{c}\mathrm{HAI}^{\mathrm{d}}, \mathrm{ADE}^{\mathrm{e}}, \\
\mathrm{LOS}^{\mathrm{f}}>7 \text { days } \\
\text { [Cluster } 2] \\
\text { OR }(95 \% \mathrm{Cl})\end{array}$ & $\begin{array}{c}\text { Readmission } \\
{\text { within } 30 \text { days }^{\mathrm{h}}}^{\text {OR }(95 \% \mathrm{Cl})}\end{array}$ \\
\hline$\geq 4$ active comorbid conditions ${ }^{9}$ & $0.87(0.32,2.38)$ & $2.46(1.15,5.24)$ & $1.58(0.71,3.53)$ \\
\hline Admitted from a skilled nursing facility & $0.40(0.05,3.14)$ & $1.35(0.54,3.39)$ & $1.61(0.59,4.44)$ \\
\hline Ages 80 years and older & $0.54(0.14,2.11)$ & $2.60(0.98,6.91)$ & $1.39(0.53,3.61)$ \\
\hline Altered mental status & $1.62(0.44,6.04)$ & $0.91(0.34,2.46)$ & $0.92(0.29,2.89)$ \\
\hline Anemia & $1.49(0.60,3.71)$ & $2.40(1.32,4.37)$ & $2.37(1.20,4.69)$ \\
\hline Charlson Comorbidity Index Score $>=4$ & $0.56(0.20,1.60)$ & $1.54(0.84,2.82)$ & $1.56(0.79,3.06)$ \\
\hline Cognitive impairment & $0.27(0.08,0.96)$ & $2.31(1.27,4.22)$ & $0.78(0.38,1.57)$ \\
\hline Deconditioning & $0.31(0.04,2.39)$ & $1.88(0.84,4.25)$ & $0.86(0.31,4.43)$ \\
\hline Decubitus ulcer present at admission & $1.21(0.26,5.69)$ & $3.62(1.31,10.01)$ & $3.31(1.15,9.47)$ \\
\hline Dehydration & $1.18(0.47,2.94)$ & $1.65(0.91,2.98)$ & $1.55(0.79,3.01)$ \\
\hline Delirium & $1.73(0.00,10.53)$ & $0.76(0.08,7.45)$ & $1.24(0.13,12.16)$ \\
\hline Depression screen positive* & $1.00(0.38,2.62)$ & $1.85(0.95,3.59)$ & $1.51(0.73,3.11)$ \\
\hline Feeding tube present at admission & $1.33(0.16,11.46)$ & $4.06(0.94,17.51)$ & $1.24(0.24,6.36)$ \\
\hline Functional impairment & $0.53(0.19,1.49)$ & $2.46(1.35,4.49)$ & $2.29(1.17,4.48)$ \\
\hline Hyponatremia & $1.02(0.22,4.75)$ & $1.60(0.62,4.13)$ & $3.52(1.36,9.13)$ \\
\hline Hypoalbuminemia & $1.17(0.32,4.28)$ & $2.41(1.06,5.47)$ & $0.91(0.32,2.58)$ \\
\hline Potentially inappropriate medications & $2.93(1.17,7.34)$ & $0.91(0.49,1.69)$ & $1.13(0.57,2.27)$ \\
\hline Use of a major tranquilizer & $2.28(0.89,5.88)$ & $1.15(0.58,2.28)$ & $1.47(0.70,3.08)$ \\
\hline Polypharmacy** & $0.75(0.28,1.99)$ & $1.08(0.60,1.95)$ & $1.02(0.53,1.98)$ \\
\hline \multicolumn{4}{|l|}{ Recent admissions: } \\
\hline$>1$ within the past 30 days & $0.41(0.12,1.44)$ & $1.39(0.74,2.64)$ & $2.95(1.48,5.87)$ \\
\hline$\geq 2$ within the past 6 months & $0.74(0.22,2.42)$ & $1.64(0.84,3.20)$ & $1.75(0.84,3.66)$ \\
\hline Recent unintentional weight loss & $3.68(1.43,9.46)$ & $2.98(1.48,6.02)$ & $1.02(0.44,2.32)$ \\
\hline
\end{tabular}

${ }^{\mathrm{a}} \mathrm{HAPU}=$ hospital-acquired pressure ulcer(s); ${ }^{\mathrm{b}} \mathrm{PC}=$ procedural complications; ${ }^{\mathrm{C}} \mathrm{ICU}=$ intensive care unit; ${ }^{\mathrm{e}} \mathrm{HAI}=$ hospital-acquired infection(s); ${ }^{\mathrm{f}} \mathrm{LOS}=\mathrm{Length}$ of hospital stay. ${ }^{9}$ At least one of the conditions was required to be "uncontrolled" (not at therapeutic goal). "Three patients died during admission and were excluded from the analysis of readmissions. Complete data available from only $(*) n=178$ or $\left(^{* *}\right) n=205$. quality indicators (QIs) for common geriatric issues lags behind that of other medical conditions [34,35]. Among 349 hospital patients ages 65 years and older meeting VES13 criteria for vulnerability, Arora et al. found that QIs for delirium and dementia were satisfied less frequently than QIs for general medical care (31.4\% and 81.5\%, respectively) [35]. Jencks et al. reported that over a 15-month period between 2003 and 2004, nearly one-fifth of all Medicare beneficiaries were readmitted within 30 days of hospital discharge. Such unplanned readmissions accounted for an estimated $17 \%$ of the $\$ 102.6$ billion in hospital payments made by Medicare in 2004 [36].

In order to be useful for a prompt response and risk mitigation efforts, we limited our investigation to risk factors that were recognizable within 24 hours of hospital admission. Attributes commonly associated with frailty are highly prevalent among the elderly population, and therefore potentially useful for studies of risk factors for adverse events among hospitalized Medicare patients [3]. Searle 
Table 4 Multivariable logistic regression models for characteristics associated with adverse hospital outcomes

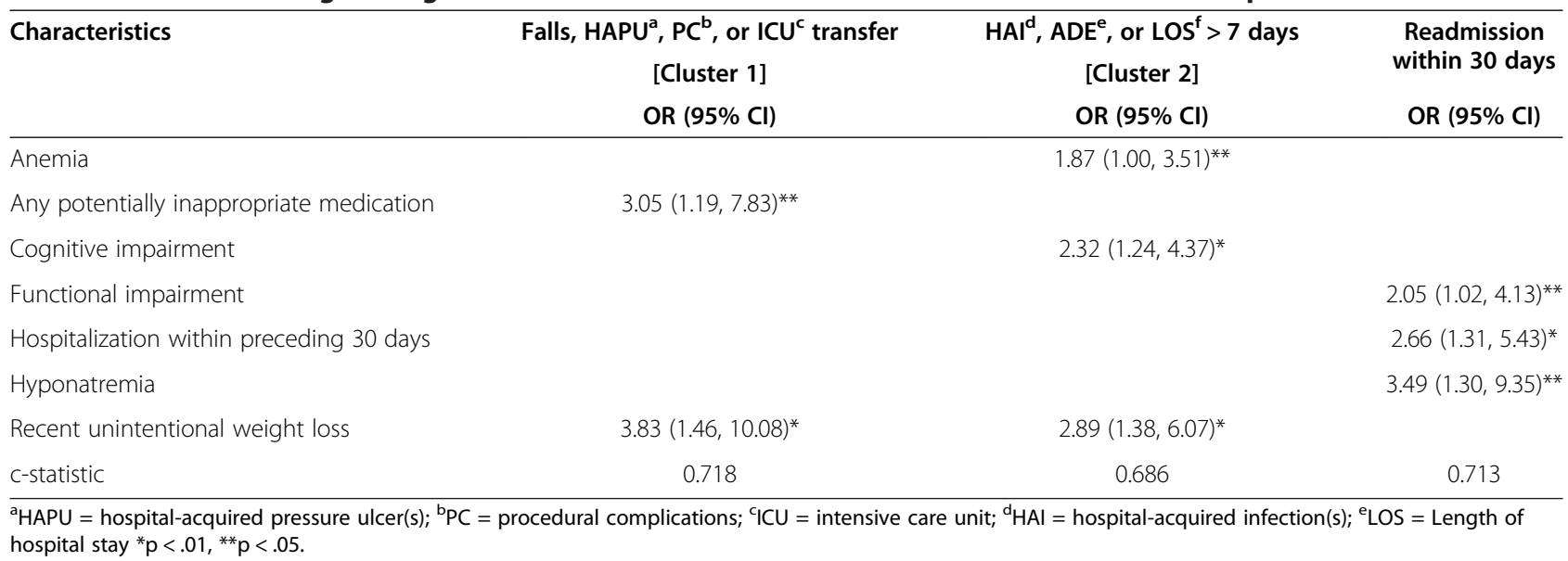

et al. described a standardized process for developing frailty indices by examining the association of specific deficit and mortality in a community-dwelling cohort [37]. As noted in a position statement of the American Geriatrics Society (AGS), interdisciplinary assessment and care have been shown to improve health outcomes in the elderly in a variety of settings [38]. Combining these two concepts, we employed multidisciplinary consensus to select among a large number of potential frailty traits, and then examined associations with adverse events occurring more commonly in the elderly.

Initiated as part of a quality improvement effort at our institution, this strategy follows a practical approach to identifying vulnerability within a hospitalized population that is broadly applicable [37]. The observed clustering of outcomes minimizes the sample size required for statistical modeling. This phenomenon, together with the use of readily identifiable patient characteristics, makes these types of analyses feasible, even in resource-constrained environments. The value of such efforts, however, will depend entirely on future demonstration of their usefulness in facilitating effective risk reduction.

Our approach differed from prior work in that we used prospective data, and focused on characteristics present early in hospitalization. A recent systematic review of risk prediction models of readmission by Kasangra et al. identified only two contemporary studies that used real-time data [39]. Neither model included information available within 24 hours of admission [40,41]. We observed that health issues readily identifiable on admission hyponatremia, functional impairment, and prior admission within 30 days - were associated with early readmission, and distinct from predictors of adverse events during hospitalization. While not typically the reason for admission to an acute care facility, these characteristics may reflect a poor state of general health. Consequently, medical management that focuses solely on the immediate causes of hospitalization may have little impact on
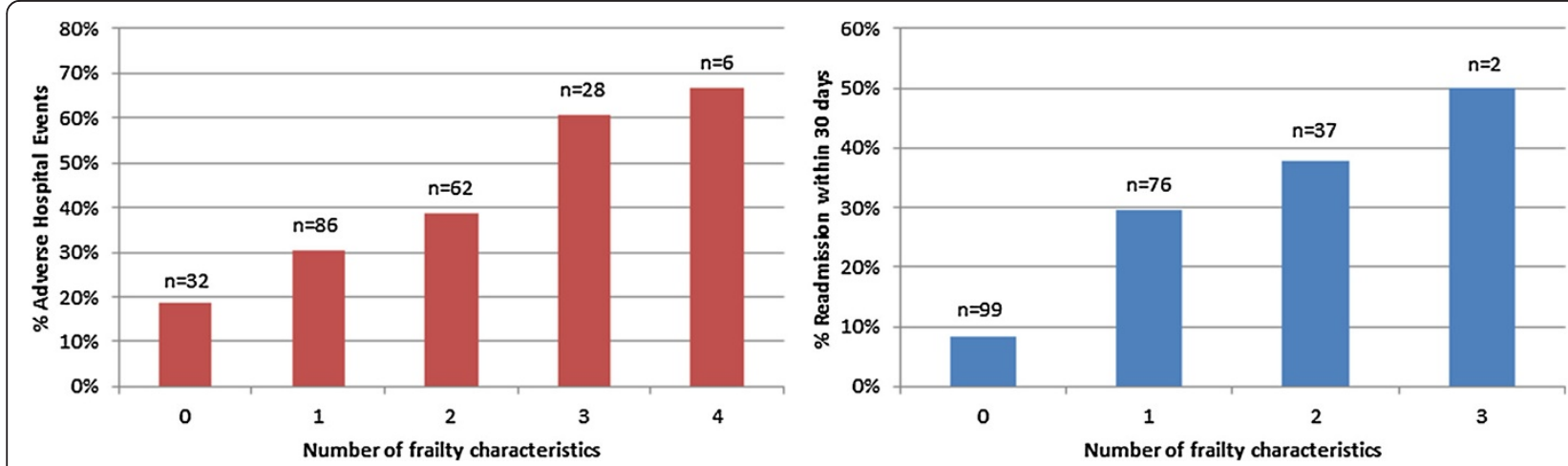

Figure 1 Proportion of adverse events and number of patient frailty characteristics. Frailty characteristics associated with adverse events during hospitalization = cognitive impairment, anemia, recent unintentional weight loss, and any potentially inappropriate medication prior to admission. $n=$ number of patients in each group. Significant test of trend, $R_{S}=0.25, p<0.001$. Frailty characteristics associated with readmission within 30 days = hyponatremia, hospitalization within previous 30 days, and functional impairment. $n=$ number of patients in each group. Significant test of trend, $R_{S}=0.31, p<0.001$. 
underlying frailty, and leave patients more susceptible to poor short and long-term outcomes, such as unplanned rehospitalizations and institutionalization. It is possible that discharge planning that includes strategies to address these risk factors could help to reduce early hospital readmission.

The results of this analysis reconfirmed some characteristics that have been found to be independently associated with adverse health outcomes in other studies. Prior hospital admission within 30 days [17] and impaired functional status as measured by the Katz Scale [42] predict readmission within 30 days of discharge. Weight loss $\geq 10$ pounds defines an increased risk of malnutrition that is associated with a higher incidence of falls [43] and longer hospital stays [44]. Similarly, inpatient falls occur more frequently in patients prescribed potentially inappropriate medications [25], and the presence of either anemia or cognitive impairment increases the likelihood of prolonged hospitalization [45]. Community-acquired hyponatremia is associated with inpatient mortality, increased length of stay, and discharge to short or long-term care facilities [46]. To our knowledge a relationship between hyponatremia and early readmissions has not been previously described in an unselected population.

This research has several limitations. We conducted a comprehensive search of the peer-reviewed literature using general terms to increase sensitivity but did not perform a systematic review, increasing the likelihood that some characteristics of a frailty may have been overlooked. Use of a convenience cohort of patients may have introduced selection bias. Not all potential risk factors were collected in every patient due to the practicality of conducting interviews in an acutely ill population, creating a potential for response bias, particularly for the VES-13 questionnaire. As patients were identified up to 24 hours following admission, the observed association of specific characteristics with the risk of adverse outcomes may have been confounded by the care patients received between admission and assessment. The association of patient characteristics and adverse events may be influenced by differences in processes of care, particularly in the structured environment of hospitals. Hospital-based risk mitigation strategies may be applied more uniformly than in ambulatory settings, yet differ substantially among institutions. Consequently, the generalizability of our findings is unclear. However, the utility of identifying at-risk populations very early in the course of hospitalization is self-evident.

The outcomes included in this analysis are subject to the influence of the actions of different health care disciplines. For example, the incidence of falls may be affected by risk recognition and mitigation by nursing, or medications prescribed by physicians [25]. In a systematic review by Cameron et al., multifactorial interventions were associated with a relative risk of falls among hospitalized patients of $\mathrm{RR}=0.73$ ( $95 \% \mathrm{CI} 0.56$ to $0.96: \mathrm{I}^{2}=43 \%$ ) in comparison to controls [47] Similarly, incidence of hospital-acquired infections may reflect physician decisions, such as placement of a urinary catheter, or nurses' efforts to reduce the potential for catheter-acquired urinary tract infections. The 2009 National Healthcare Quality Report of the Agency for Healthcare Quality and Research emphasized multidisciplinary teams as a key strategy for reducing HAIs [48]. Bergkvist et al. also found that teams comprised of physicians, nurses, and pharmacists reduced the use of inappropriate medications in hospitalized elderly patients [49]. Collectively, these observations support the potential benefit of an interdisciplinary approach to frailty in hospitalized patients.

Many attributes of frailty prevalent among Medicare beneficiaries can result from potentially remediable conditions, such as functional impairment, and are neither universally irreversible nor synonymous with aging [50]. Early recognition of these characteristics during hospitalization is feasible, and affords the potential to identify and address underlying health issues that may contribute to adverse events. These findings may have implications for the development of targeted hospital-based safety and quality improvement programs, and may also be relevant to postacute care.

\section{Conclusions}

In conclusion, among Medicare beneficiaries, characteristics identifiable within 24 hours of hospital admission are associated with adverse hospitalizations and readmission within 30 days of discharge.

\section{Additional file}

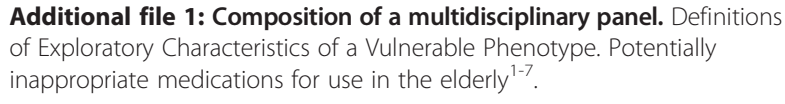

\section{Competing interests}

The authors declare that they have no competing interests.

\section{Authors' contributions}

$J B$ and HUA contributed equally to this work and both had full access to all of the data used in the study. Both contributed to the conception, design and acquisition of data. Both worked with CB (Biostatistician responsible for the data analysis) to interpret the findings. JC contributed to all pharmaceutical data collection and analysis as well as to the presentation of the pharmaceutical aspects in this manuscript. Both LBB and GDB contributed to the conception and design and general oversight of data collection, analysis and the drafting of the manuscript. None of the authors have any conflict of interest, including specific financial interests and relationships and affiliations relevant to the subject matter or materials discussed in the manuscript. No funding sources have contributed to any part of this work. All authors read and approved the final manuscript.

\section{Acknowledgements}

The authors wish to thank the following individuals for their contribution to the conceptual development and design of the study: Jeanne T. Black, PhD, 
MBA; Kathleen Burgner, MSN, MBA,RN; Rita Hand, MSN, GNP-BC, CHPN; Betty Johnson, RN; Heather D. Jones, MD; Lawrence S. Maldonado, MD; Gayla Nielson, RN, PhD; Katherine A. Palmer, PharmD; Richard V. Riggs, MD; Pamela Roberts, PhD, OTR/L; Bradley T. Rosen, MD, MBA; Rita Shane, PharmD; Daniel Stone, MD, MPH, MBA; Jane W. Swanson, PhD, RN and Clement Yang, MD. The authors thank the following for assistance with Data Collection: Erlyn R. Munda, RN-BC; Jocelyn Z. Uy, BSN; Ronnie Wong, MPH, MSW; Allyson Lazar; Laura Hardy, RN; Loryn Tracy, RN; Amanda Ewing, MD; Andrea Censullo, MD; Anish Desai, MD; Brenda Hermogeno, MD; Jeannie Seu-Giordano, MD; Robert I Goodman, MD; Shelley Yee, MD; Sid Anand, MD, MBA; Margaret H. Ochner, MD, MPH and Justin P. Lee, MD. The authors thank Rebecca Cohen, MPH for editing assistance and Jonas B. Green, MD, MPH, MSHS for manuscript review. Dr. Borenstein affirms that all who have contributed significantly to this work have been acknowledged.

\section{Author details}

${ }^{1}$ Applied Health Services Research, Cedars-Sinai Health System, 8700 Beverly Blvd, Los Angeles, CA 90048, USA. ${ }^{2}$ Nursing Research, Cedars-Sinai Health System, 8700 Beverly Blvd, Los Angeles, CA 90048, USA. ${ }^{3}$ Cedars-Sinai Health System, 8700 Beverly Blvd, Los Angeles, CA 90048, USA.

Received: 21 August 2012 Accepted: 25 June 2013

Published: 8 July 2013

\section{References}

1. Institute of Medicine: To Err Is Human: Building a Safer Health System. Washington, DC: The National Academies Press; 1999

2. Department of Health and Human Services: Office of Inspector General. Adverse events in hospitals: national incidence among Medicare beneficiaries. Washington (DC) HHS. 2010. http://oig.hhs.gov/oei/reports/oei-06-09-00090. pdf [Accessed 1/23/2013].

3. Song X, Mitnitski A, Rockwood K: Prevalence and 10-year outcomes of frailty in older adults in relation to deficit accumulation. J Am Geriatr Soc 2010, 58(4):681-687.

4. Covinsky KE, Palmer RM, Fortinsky RH, Counsell SR, Stewart AL, Kresevic D, Burant CJ, Landefeld CS: Loss of independence in activities of daily living in older adults hospitalized with medical illnesses: Increased vulnerability with age. J Am Geriatr Soc 2003, 51(4):451-458.

5. Silverstein MD, Qin H, Mercer SQ, Fong J, Haydar Z: Risk factors for 30-day hospital readmission in patients $>/=65$ years of age. Proc (Bayl Univ Med (ent). 2008, 21(4):363-372.

6. Robinson TN, Eiseman B, Wallace Jl, Church SD, McFann KK, Pfister SM, Sharp TJ, Moss M: Redefining geriatric preoperative assessment using frailty, disability and co-morbidity. Ann Surg 2009, 250(3):449-455.

7. Abellan Van Kan G, Rolland Y, Houles M, Gillette-Guyonnet $\mathrm{S}$, Soto M, Vellas B: The assessment of frailty in older adults. Clin Geriatr Med 2010, 26(2):275-286

8. Sternberg SA, Wershof Schwartz A, Karunananthan S, Bergman H, Mark CA The identification of frailty: a systematic literature review. J Am Geriatr Soc 2011, 59(11):2129-2138.

9. Hubbard RE, O'Mahony MS, Woodhouse KW: Characterising frailty in the clinical setting-025EFa comparison of different approaches. Age Ageing 2009, 38(1):115-119.

10. Fried $L P$, Tangen $C M$, Walston J, Newman AB, Hirsch C, Gottdiener J, Seeman T, Tracy R, Kop WJ, Burke G, et al: Frailty in older adults: Evidence for a phenotype. J Gerontol a-Biol 2001, 56(3):M146-M156.

11. Saliba D, Elliott M, Rubenstein LZ, Solomon DH, Young RT, Kamberg CJ, Roth C, MacLean CH, Shekelle PG, Sloss EM, et al: The Vulnerable Elders Survey: a tool for identifying vulnerable older people in the community. J Am Geriatr Soc 2001, 49(12):1691-1699.

12. Rockwood K, Song X, MacKnight C, Bergman H, Hogan DB, McDowell I, Mitnitski A: A global clinical measure of fitness and frailty in elderly people. CMAJ 2005, 173(5):489-495

13. Ensrud KE, Ewing SK, Cawthon PM, Fink HA, Taylor BC, Cauley JA, Dam TT, Marshall LM, Orwoll ES, Cummings SR: A comparison of frailty indexes for the prediction of falls, disability, fractures, and mortality in older men. J Am Geriatr Soc 2009, 57(3):492-498.

14. Lacas A, Rockwood K: Frailty in primary care: a review of its conceptualization and implications for practice. BMC Med 2012, $10: 4$.
15. Herrmann FR, Osiek A, Cos M, Michel JP, Robine JM: Frailty judgment by hospital team members: degree of agreement and survival prediction. J Am Geriatr Soc 2005, 53(5):916-917.

16. Levers MJ, Estabrooks CA, Ross Kerr JC: Factors contributing to frailty: literature review. J Adv Nurs 2006, 56(3):282-291.

17. Marcantonio ER, McKean S, Goldfinger M, Kleefield S, Yurkofsky M, Brennan TA: Factors associated with unplanned hospital readmission among patients 65 years of age and older in a Medicare managed care plan. Am J Med 1999, 107(1):13-17.

18. Mehta KM, Pierluissi E, Boscardin WJ, Kirby KA, Walter LC, Chren MM, et al: A clinical index to stratify hospitalized older adults according to risk for new-onset disability. J Am Geriatr Soc 2011, 59(7):1206-1216.

19. Jones SR: Infections in Frail and Vulnerable Elderly Patients. Am J Med 1990, 88(3C):S30-S33.

20. Laniece I, Couturier P, Drame M, Gavazzi G, Lehman S, Jolly D, Voisin T, Lang PO, Jovenin N, Gauvain JB, Novellu J, Saint-Jean O, Blanchard F: Incidence and main factors associated with early unplanned hospital readmission among French medical inpatients aged 75 and over admitted through emergency units. Age Ageing 2008, 37(4):416-422.

21. Katz S: Assessing Self-Maintenance - Activities of Daily Living, Mobility, and Instrumental Activities of Daily Living. J Am Geriatr Soc 1983, 31(12):721-727.

22. Saliba DBJ: Development and validation of a revised nursing home assessment tool: MDS 3.0. Rand Health Corporation. 2008. http://www.cms.gov/Medicare/ Quality-Initiatives-Patient-Assessment-Instruments/NursingHomeQualitylnits/ downloads/MDS30FinalReport.pdf (Accessed 1/24/2013).

23. Kroenke K, Spitzer RL, Williams JBW: The Patient Health Questionnaire-2 - Validity of a two-item depression screener. Medical Care 2003, 41(11):1284-1292.

24. Fick DM, Cooper JW, Wade WE, Waller JL, Maclean JR, Beers MH: Updating the Beers criteria for potentially inappropriate medication use in older adults: results of a US consensus panel of experts. Arch Intern Med 2003, 163(22):2716-2724

25. Woolcott JC, Richardson KJ, Wiens MO, Patel B, Marin J, Khan KM, Marra CA: Meta-analysis of the Impact of 9 Medication Classes on Falls in Elderly Persons. Arch Intern Med 2009, 169(21):1952-1960.

26. Rozich JD, Haraden CR, Resar RK: Adverse drug event trigger tool: a practical methodology for measuring medication related harm. Qual Saf Health Care 2003, 12(3):194-200.

27. Rencher AC: Methods of multivariate analysis. 2nd edition. New York: J. Wiley; 2002

28. Collett D: Modelling survival data in medical research. 2nd edition. Boca Raton, Fla: Chapman \& Hall/CRC; 2003.

29. Institute of Medicine: Allied Health Workforce and Services. Washington, DC: Workshop Summary; 2011.

30. Chattopadhyay A, Bindman AB: Linking a comprehensive payment model to comprehensive care of frail elderly patients: a dual approach. JAMA 2010, 304(17):1948-1949.

31. Kleinpell RMF, Kathy J, Bonnie M, Chapter 11: Reducing Functional Decline in Hospitalized Elderly. In An evidence-based handbook for Nurses. Edited by Quality AfHRa. Rockville, MD: Patient Safety and Quality; 2008.

32. Broyles RW, Chou AF, Mattachione S, Wild RC, Al-Assaf AF: The effect of adverse medical events on spending on inpatient care. Qual Manag Health Care 2009, 18(4):315-325.

33. Covinsky KE, Pierluissi E, Johnston CB: Hospitalization-associated disability: "She was probably able to ambulate, but I'm not sure". JAMA 2011, 306(16):1782-1793.

34. Podulka JB, Marguerite J, Steiner C: 30-Day Readmissions following Hospitalizations for Chronic vs. Acute Conditions. Rockville: 2008. H-CUP Healthcare Cost And Utilization Project; 2012.

35. Arora VM, Johnson M, Olson J, Podrazik PM, Levine S, Dubeau CE, Sachs GA, Meltzer DO: Using assessing care of vulnerable elders quality indicators to measure quality of hospital care for vulnerable elders. J Am Geriatr Soc 2007, 55(11):1705-1711.

36. Jencks SF, Williams MV, Coleman EA: Rehospitalizations among Patients in the Medicare Fee-for-Service Program REPLY. New Engl J Med 2009, 361(3):312-312.

37. Searle SD, Mitnitski A, Gahbauer EA, Gill TM, Rockwood K: A standard procedure for creating a frailty index. BMC Geriatr 2008, 8:24.

38. Mion L, Odegard PS, Resnick B, Segal-Galan F: Interdisciplinary care for older adults with complex needs: American Geriatrics Society position statement. J Am Geriatr Soc 2006, 54(5):849-852. 
39. Kansagara D, Englander H, Salanitro A, Kagen D, Theobald C, Freeman M, Kripalani S: Risk prediction models for hospital readmission: a systematic review. JAMA 2011, 306(15):1688-1698.

40. Allaudeen N, Schnipper JL, Orav EJ, Wachter RM, Vidyarthi AR: Inability of providers to predict unplanned readmissions. J Gen Intern Med 2011 26(7):771-776

41. Hasan O, Meltzer DO, Shaykevich SA, Bell CM, Kabai PJ, Auerbach AD, Wetterneck TB, Arora VM, Zhang J, Schnipper JL: Hospital readmission in general medicine patients: a prediction model. J Gen Intern Med 2010, 25(3):211-219.

42. Sullivan DH: Risk factors for early hospital readmission in a select population of geriatric rehabilitation patients: the significance of nutritional status. J Am Geriatr Soc 1992, 40(8):792-798.

43. Bauer JD, Isenring E, Torma J, Horsley P, Martineau J: Nutritional status of patients who have fallen in an acute care setting. J Hum Nutr Diet 2007, 20(6):558-564

44. Ferguson M, Capra S, Bauer J, Banks M: Development of a valid and reliable malnutrition screening tool for adult acute hospital patients. Nutrition 1999, 15(6):458-464

45. Lang PO, Heitz D, Hedelin G, Drame M, Jovenin N, Ankri J, Somme D, Novella $\mathrm{J}$, Gauvain JB, Couturier $\mathrm{P}$, et al: Early markers of prolonged hospital stays in older people: a prospective, multicenter study of 908 inpatients in French acute hospitals. J Am Geriatr Soc 2006, 54(7):1031-1039.

46. Wald R, Jaber BL, Price LL, Upadhyay A, Madias NE: Impact of hospitalassociated hyponatremia on selected outcomes. Arch Intern Med 2010, 170(3):294-302.

47. Cameron ID, Murray GR, Gillespie LD, Robertson MC, Hill KD, Cumming RG, Kerse N: Interventions for preventing falls in older people in nursing care facilities and hospitals. Cochrane Database Syst Rev 2010, 1, CD005465.

48. Agency for Healthcare Research and Quality: National Healthcare Quality Report: 2009. Publication No. 10-0003. Rockville, MD: US Dept. of Health and Human Services; 2010.

49. Bergkvist A, Midlov P, Hoglund P, Larsson L, Eriksson T: A multi-intervention approach on drug therapy can lead to a more appropriate drug use in the elderly. J Eval Clin Prac 2009, 15(4):660-667.

50. Lang IA, Hubbard RE, Andrew MK, Llewellyn DJ, Melzer D, Rockwood K: Neighborhood deprivation, individual socioeconomic status, and frailty in older adults. J Am Geriatr Soc 2009, 57(10):1776-1780.

doi:10.1186/1471-2318-13-72

Cite this article as: Borenstein et al.: Early recognition of risk factors for adverse outcomes during hospitalization among Medicare patients: a prospective cohort study. BMC Geriatrics 2013 13:72.

\section{Submit your next manuscript to BioMed Central and take full advantage of:}

- Convenient online submission

- Thorough peer review

- No space constraints or color figure charges

- Immediate publication on acceptance

- Inclusion in PubMed, CAS, Scopus and Google Scholar

- Research which is freely available for redistribution 